\title{
A COLEÇÃo dA BIBLIOTECA ESCOLAR NA PERSPECTIVA DOS PARÂMETROS CURRICULARES NACIONAIS
}

\author{
Bernadete Santos Campello \\ Carlos Henrique de Magalhães \\ Giovanna Vasconcellos Xavier \\ Leonardo da Costa Diskin \\ Márcia Margarida Vilaça \\ Simone Alves Diamantino \\ Sirlene Aparecida dos Santos \\ Waldete Rodrigues dos Santos
}

Resumo

Os Parâmetros Curriculares Nacionais (PCN) constituem diretrizes para a reestruturação curricular das escolas de ensino fundamental e educação infantil no Brasil. A proposta dos PCN é de um ensino baseado na perspectiva construtivista e, para tanto, a escola precisa contar com material didático variado. Considerando que a biblioteca é o local por excelência para reunião e compartilhamento desses materiais, procura-se, neste trabalho, delinear o perfil da coleção de uma biblioteca comprometida com metodologias de aprendizagem inovadoras. Identifica nos PCN os materiais e as temáticas sugeridas e, a partir daí, delineouse o perfil da coleção.

Palavras chave

Biblioteca escolar; Material didático; Leitura; Parâmetros Curriculares Nacionais. 


\section{INTRODUÇÃO}

Os Parâmetros Curriculares Nacionais $(\mathrm{PCN})$ relativos à educação infantil e ao ensino fundamental constituem referencial que a Secretaria de Educação Fundamental do MEC coloca à disposição dos educadores brasileiros para reorientação curricular.

Apoiado fortemente no conceito de cidadania, os PCN buscam criar condições para que crianças e jovens brasileiros tenham acesso ao saber socialmente elaborado e reconhecido como necessário ao exercício dessa cidadania.

Segundo Ezequiel Silva, "este saber não encontra na oralidade o seu principal meio de transmissão e circulação; esse saber encontra-se registrado através da escrita e é pelo trampolim da escrita que ele pode ser recuperado, estudado, pesquisado, etc... para as propostas de ensino-aprendizagem" (SILVA, 1997, p. 55).

Tendo como marco explicativo a perspectiva construtivista de aprendizagem, os PCN se apóiam na premissa de que "o conhecimento surge e se enraíza através da ação e da interação dos sujeitos (professores e/ou alunos) com os objetos a serem apreendidos pela consciência. $\mathrm{O}$ ato de aprender, portanto, exige do aprendiz, ação concreta e diálogo concreto com os suportes que veiculam elementos do saber constituído historicamente" (SILVA, 1997, p. 56).

Ao longo dos 23 volumes dos PCN, esses suportes são mencionados na perspectiva de sua utilização como recurso didático, que apóia a aprendizagem baseada na construção do conhecimento pelo aluno.

Em artigo anterior de Campello (2000a), vimos que, na perspectiva dos $\mathrm{PCN}$, a aprendizagem é fortemente baseada na biblioteca, que é considerada não só como apoio às atividades ligadas à leitura, mas como espaço de busca de informação e como influência modelizadora para que os alunos desenvolvam habilidades de usar informação, habilidades que irão capacitálos para aprender de maneira independente e contínua.

Considerando-se que a biblioteca constitui geralmente o espaço coletivo que abriga os suportes, procurando garantir seu acesso de forma democrática, a questão que o presente trabalho visa explorar é a seguinte: de que maneira os PCN visualizam a utilização dos suportes $\mathrm{e}$, consequentemente como a biblioteca deverá atuar na formação de um acervo que apóie efetivamente o projeto pedagógico da instituição escolar?

Para responder a essa questão foi realizado, nos volumes dos PCN relativos ao ensino fundamental e à educação infantil, um levantamento de todas as recomendações sobre utilização de recursos bibliográficos e fontes de informação. Essas recomendações foram analisadas e relacionadas à concepção de aprendizagem de cada área. O texto foi organizado por área e dentro de cada área por nível (educação infantil e ensino fundamental), traçando-se um perfil do acervo da biblioteca escolar necessária a um projeto pedagógico nos moldes sugeridos pelos $\mathrm{PCN}$.

\section{LINGUAGEM}

A aprendizagem da linguagem oral $e$ escrita é considerada pelos $\mathrm{PCN}$ como elemento importante na ampliação das possi- 
bilidades de inserção e participação da criança e do jovem nas práticas sociais, na construção de conhecimentos e no desenvolvimento do pensamento.

$\mathrm{Na}$ educação infantil a aprendizagem da língua leva a criança a, gradativamente, ampliar suas capacidades de comunicação e expressão e de acesso ao mundo letrado.

A aprendizagem das competências lingüísticas básicas (falar, escutar, ler e escrever) é feita com base no texto. É fundamental que seja dada à criança oportunidade de ter contato com a diversidade textual e de gêneros, devendo os textos ser apresentados nos seus portadores originais. Isso permitirá que desde o início de sua escolarização a criança perceba a utilização que se faz da escrita em diferentes circunstâncias, observando as condições nas quais é produzida, suas várias funções e características.

Os textos literários têm um lugar especial, embora não exclusivo, nas atividades com a linguagem, segundo os PCN. A leitura e a escuta de histórias permeiam todo o período de escolarização, desde os primeiros anos, mesmo antes de a criança dominar o código lingüístico, quando busca-se construir uma atitude de curiosidade pelo livro e de prazer pela leitura. Isso se consegue com a utilização de textos bem selecionados, criativos, ricos e com ilustrações de qualidade.

A familiaridade com a diversidade de gêneros é muito enfatizada nos PCN no que diz respeito à aprendizagem da língua. Deve-se, inclusive permitir às crianças conhecer a diversidade dentro de um mesmo gênero, por exemplo, trabalhando-se com o conjunto da obra de determinado autor ou com as várias versões de um mesmo conto ou lenda.
Outros materiais recomendados pelos PCN para atividades de linguagem na fase de educação infantil são: jornais, revistas, enciclopédias, dicionários, almanaques, palavras cruzadas, livros de receitas culinárias, contos, mitos, lendas, "causos" populares, fábulas, relatos históricos, além de uma variedade de artefatos gráficos como textos de embalagens, rótulos, anúncios, slogans, cartazes, folhetos, cartas, bilhetes, cartões, convites etc. Atividades constantes e sistemáticas com base em alguns desses materiais irão desvelar para a criança o universo informacional diversificado hoje disponível, levando-a ao entendimento das peculiaridades de cada um.

No ensino fundamental espera-se que o aluno, gradativamente, amplie o domínio ativo do discurso nas diversas situações comunicativas, com ênfase naquelas que ocorrem nas instâncias públicas de uso da linguagem, de modo a possibilitar sua inserção efetiva no mundo da escrita.

O texto continua a ser a unidade básica de ensino mas, dada a grande diversidade de gêneros disponíveis, os PCN recomendam que a escola faça uma seleção e sugerem alguns gêneros que devem ser priorizados em função das possibilidades que oferecem para um trabalho pedagógico que leve à efetiva participação social do aluno. Os quadros a seguir apresentam os gêneros sugeridos pelos PCN, agrupados em função de sua circulação social, nas seguintes categorias: literários, de imprensa, publicitários e de divulgação científica. 
Gêneros privilegiados para a prática de escuta e leitura de textos

\begin{tabular}{|c|c|c|}
\hline & Linguagem oral & Linguagem escrita \\
\hline Literários & $\begin{array}{l}\text { Cordel, "causos" e } \\
\text { similares } \\
\text { Texto dramático } \\
\text { Canção }\end{array}$ & $\begin{array}{l}\text { Conto } \\
\text { Romance } \\
\text { Novela } \\
\text { Crônica } \\
\text { Poema } \\
\text { Texto dramático }\end{array}$ \\
\hline De imprensa & $\begin{array}{l}\text { Comentário radiofônico } \\
\text { Entrevista } \\
\text { Debate } \\
\text { Palestra }\end{array}$ & $\begin{array}{l}\text { Notícia } \\
\text { Editorial } \\
\text { Artigo } \\
\text { Reportagem } \\
\text { Carta do leitor } \\
\text { Entrevista } \\
\text { Charge e tira } \\
\end{array}$ \\
\hline De divulgação científica & $\begin{array}{l}\text { Exposição } \\
\text { Seminário } \\
\text { Debate palestra }\end{array}$ & $\begin{array}{l}\text { Verbete enciclopédico } \\
\text { (nota/artigo) } \\
\text { Relatório de experiências } \\
\text { Didático (textos, } \\
\text { enunciados de questões) } \\
\text { Artigo }\end{array}$ \\
\hline Publicidade & Propaganda & Propaganda \\
\hline
\end{tabular}

Fonte: Parâmetros Curriculares Nacionais $1^{\text {a }}$ a $5^{\text {a }}$ séries, p. 54 


\section{Gêneros sugeridos para a prática de produção de textos orais e escritos}

\begin{tabular}{|c|c|c|}
\hline & Linguagem oral & Linguagem escrita \\
\hline Literários & $\begin{array}{l}\text { Canção } \\
\text { Texto dramático }\end{array}$ & $\begin{array}{l}\text { Crônica } \\
\text { Conto } \\
\text { Poema }\end{array}$ \\
\hline De imprensa & $\begin{array}{l}\text { Notícia } \\
\text { Entrevista } \\
\text { Debate } \\
\text { Depoimento }\end{array}$ & $\begin{array}{l}\text { Notícia } \\
\text { Artigo } \\
\text { Carta do leitor } \\
\text { Entrevista }\end{array}$ \\
\hline De divulgação científica & $\begin{array}{l}\text { Exposição } \\
\text { Seminário } \\
\text { Debate }\end{array}$ & $\begin{array}{l}\text { Relatório de experiências } \\
\text { Esquema e resumo de } \\
\text { artigos ou verbete de } \\
\text { enciclopédia }\end{array}$ \\
\hline
\end{tabular}

Fonte: Parâmetros Curriculares Nacionais $1^{\mathrm{a}}$ a $5^{\mathrm{a}}$ séries, p. 57

Observa-se que o trabalho com a linguagem oral, tanto de escuta quanto de produção de texto, vai demandar que a biblioteca inclua em seu acervo audiovisuais de gêneros variados, conforme o quadro sugere.

O texto literário continua a ter um lugar reservado na aprendizagem da língua. Constituindo uma forma peculiar de representação e estilo em que predominam a força criativa da imaginação e a intenção estética, o texto literário enraíza-se no imaginário e constrói novas hipóteses e metáforas explicativas, possibilitando uma for- ma diferente de apreensão do conhecimento. Assim, a biblioteca deve investir em livros de literatura de qualidade que ajudarão a criança, ao longo dos oito anos do ensino fundamental, a se transformar de um leitor esporádico em um leitor contumaz, ou seja, que estabeleça vínculos cada vez mais estreitos entre um texto e outros, e que construa referências sobre o funcionamento da literatura, ampliando constantemente seus modos de ler.

A aprendizagem da língua prevê que o aluno desenvolva habilidades de empregar estratégias não lineares durante o 
processamento da leitura e nesse sentido ele deve aprender a consultar outras fontes em busca de informações complementares que enriqueçam sua leitura. Assim, a coleção da biblioteca deve oferecer uma variedade de fontes de referência como dicionários de língua e especiais, enciclopédias, fontes geográficas e biográficas, almanaques, gramáticas etc.

\section{CIÊNCIAS NATURAIS}

O contato com conhecimentos sobre o mundo natural começa desde a educação infantil, quando o trabalho pedagógico volta-se para a ampliação das experiências das crianças e para a construção de conhecimentos integrados sobre o meio social e natural, e se consolida, no ensino fundamental, na área de ciências naturais.

$\mathrm{Na}$ educação infantil as Ciências Naturais estão inseridas no eixo de trabalho denominado pelos PCN de Natureza e Sociedade, integrando um conjunto de temas pertinentes ao mundo social e natural, conforme mostrado no quadro abaixo.
O objetivo é levar a criança a estabelecer progressivamente a diferenciação entre explicações provenientes do senso comum e os conhecimentos científicos.

Dada a variedade de temas que o eixo Natureza e Sociedade oferece é necessário organizar o trabalho pedagógico em torno de assuntos selecionados em função de sua relevância para o grupo social com o qual se vai trabalhar.

Desde pequenas as crianças devem ser estimuladas a observar fenômenos, relatar acontecimentos e prever resultados de experimentos.

As atividades dos blocos Seres vivos, Fenômenos da natureza e Objetos e processos de transformação, sugeridos pelos PCN para compor o eixo Natureza e Sociedade podem ser trabalhadas por meio da observação direta (cultivo de plantas, observação de pequenos animais e de fenômenos como chuva, seca, arco-íris etc.) ou de forma indireta através de materiais audiovisuais (fotografias e filmes). As crianças serão levadas a perceber as lacu-

\section{Blocos de conteúdo do eixo temático Natureza e Sociedade}

\begin{tabular}{|c|}
\hline Seres vivos \\
\hline Fenômenos da natureza \\
\hline Objetos e processos de transformação \\
\hline Organização dos grupos e seu modo de ser, viver e \\
trabalhar \\
\hline Os lugares e suas paisagens \\
\hline
\end{tabular}


nas em seus conhecimentos e a preencher essas lacunas por meio de diversas fontes de informação. A coleção da biblioteca deve então estar preparada para oferecer uma variedade de materiais na forma de textos, mapas, filmes, depoimentos de pessoas, além das tradicionais enciclopédias e livros. Sites de organizações governamentais e não governamentais devem ser selecionados de forma que as crianças comecem a perceber informações divergentes ou complementares. A riqueza do acervo vai permitir também que as crianças aprendam sobre as próprias fontes de informação no que diz respeito à sua autoria, origem e época em que foram produzidas, percebendo que elas são produto da pesquisa e do trabalho de diversas pessoas.

A aprendizagem de Ciências Naturais no ensino fundamental deve levar o aluno a compreender a natureza como um todo dinâmico e o ser humano como parte inte- grante e agente de transformações no mundo em que vive. Baseada na problematização, deve ter como ponto de partida as explicações e experiências dos próprios alunos sobre os fenômenos naturais e os produtos tecnológicos com os quais convivem. Os eixos temáticos sugeridos pelos PCN para a área de Ciências Naturais (mostrados no quadro abaixo) representam conteúdos amplos cujos temas podem ser privilegiados pela escola.

As explicações e experiências trazidas pelos alunos serão questionadas através de uma intervenção desestabilizadora do professor e provavelmente irão se mostrar insuficientes para explicar determinados fenômenos. A partir daí, os alunos serão estimulados a buscar informações para reconstruir ou ampliar seus modelos. A busca de informação é, portanto, elemento importante na aprendizagem construtiva e, no caso das ciências naturais, ela pode se

\section{Eixos temáticos de Ciências Naturais para o ensino fundamental}

\begin{tabular}{|l|l|}
\hline 1. e 2. ciclos & Ambiente \\
& Ser humano \\
& Recursos tecnológicos \\
\hline 3. e 4. ciclos & Terra e universo \\
& Vida e ambiente \\
& Ser humano e saúde \\
& Tecnologia e sociedade \\
\hline
\end{tabular}


concretizar em: observação, experimentação, leitura de textos, entrevista, excursão ou estudo do meio.

Desses, a leitura de textos informativos interessa diretamente à biblioteca e sua coleção deve ser planejada de modo a oferecer acesso a uma diversidade de textos informativos de qualidade, com estrutura e finalidades diferentes e com informações divergentes. Jornais e revistas, livros de literatura e paradidáticos sobre temas relacionados, ficção científica, enciclopédias, folhetos e sites de instituições (museus, postos de saúde, organizações governamentais e não governamentais, empresas de distribuição de água e energia) são recursos informacionais que a biblioteca deve oferecer para evitar a utilização única do livro didático tradicional, com propostas limitadas e não raro equivocadas.

\section{HISTÓRIA}

A aprendizagem de História deve ocorrer desde o início da vida escolar da criança. Na educação infantil essa área se integra ao eixo denominado Natureza e
Sociedade, através do qual se procura, a partir da curiosidade, interesse e experiências das crianças, levá-las a construir um conjunto de conhecimentos sobre o mundo social e natural que a cerca. O bloco de conteúdo chamado nos PCN de Organização dos grupos e seu modo de ser, viver e trabalhar procura levar a criança a estabelecer novas formas de relação com uma diversidade de costumes e expressões culturais.

Ao lado das fontes de informação bibliográficas (livros, enciclopédias, revistas e jornais), a imagem assume importância fundamental, na medida que possibilita a observação de detalhes com mais concretude. Assim, os recursos audiovisuais, tais como slides, programas de TV, filmes, vídeos, desenhos e fotografias, constituem meios que a biblioteca precisa agregar a seu acervo, permitindo as análises de como viveram pessoas de outras épocas e grupos sociais.

No ensino fundamental os eixos temáticos sugeridos para os quatro ciclos (listados abaixo) constituem conteúdos que, trabalhados numa perspectiva construtivista

\section{Eixos temáticos de História para o ensino fundamental}

\begin{tabular}{|l|l|}
\hline 1. ciclo & História local e do cotidiano \\
\hline 2. ciclo & História das organizações populacionais \\
\hline 3. ciclo & $\begin{array}{l}\text { História das relações sociais, da cultura e } \\
\text { do trabalho }\end{array}$ \\
\hline 4. ciclo & $\begin{array}{l}\text { História das representações e das } \\
\text { relações de poder }\end{array}$ \\
\hline
\end{tabular}


e de problematização, permitirão aos alunos, gradativamente, compreender sua realidade e, confrontando-a com outras realidades históricas, posicionar-se, fazer escolhas e agir criteriosamente.

No início da alfabetização a aprendizagem é baseada em fontes orais e iconográficas, utilizando-se fotografias, mapas, filmes etc.

Quando já dominam a leitura, os alunos realizam atividades com diversas fontes de informação textual, identificando suas especificidades, em direção a maior autonomia intelectual.

A importância que os $\mathrm{PCN}$ dão ao documento primário,como fonte de informação para a aprendizagem da História, vai exigir que a biblioteca identifique e promova o acesso a outros estoques de informação, tais como arquivos, museus, coleções especializadas (obras raras, fotografias etc.), permitindo que os alunos percebam os documentos históricos como obras humanas que registram parcelas das complexas relações sociais.

As fontes secundárias, bibliográficas e não bibliográficas continuam a ter uma utilização freqüente: atividades com enciclopédias, textos de historiadores, livros didáticos, documentários e filmes históricos visam levar o aluno a obter informações de modo crítico, questionando e dialogando com os textos.

\section{GEOGRAFIA}

A percepção dos elementos que compõem a paisagem, tanto aqueles decorrentes da ação da natureza como da ação do homem, deve ser estimulada desde cedo.

Os temas geográficos podem ser tra- tados de maneira sistemática já no período de educação infantil, encorajando-se a criança a observar intencionalmente os elementos da paisagem. Esses temas estão inseridos no eixo Natureza e sociedade e são tratados no bloco Os lugares e suas paisagens.

Num primeiro momento, os temas devem relacionar-se ao cotidiano das crianças, ampliando-se gradativamente, a fim de levá-las a entender que os fenômenos da natureza por um lado condicionam a vida das pessoas e por outro as pessoas modificam a paisagem, transformando a natureza e construindo o lugar onde vivem em função de suas várias necessidades.

A aprendizagem de temas geográficos vai se basear em diversos materiais como fotografias, cartões postais, textos informativos e literários, músicas, documentários e filmes que façam referência a paisagens variadas.

Especificamente para os temas geográficos a biblioteca deve se preparar para colecionar mapas, globos, plantas de cidades e mapas para localização de lugares que permitam a familiaridade com as características da linguagem gráfica utilizada na cartografia.

No ensino fundamental, o ensino de geografia visa levar os alunos a compreender a realidade de forma ampla, levandoos a observar, conhecer, explicar, comparar e representar as características do lugar em que vivem e de diferentes paisagens e espaços geográficos. A aprendizagem de geografia nos PCN está comprometida não só em tornar o mundo compreensível para os alunos, mas também em mostrar que o mundo é passível de transformação.

O professor deve utilizar metodologias 
dinâmicas e instigantes, mediante situações que problematizem os diferentes espaços geográficos, conduzindo os alunos a observar diretamente os fenômenos a serem estudados. Pode-se usar também meios indiretos: fotografias, vídeos, relatos e mesmo obras literárias. Uma variedade de materiais pode ajudar no aprofundamento e compreensão de temas geográficos, tais como músicas regionais, fotografias aéreas, filmes e outros.

O conhecimento geográfico é registrado em fontes bem peculiares à área: os mapas e globos. A cartografia já se desenvolveu como uma disciplina auxiliar no estudo da geografia e contando com recursos atualmente oferecidos pela computação gráfica, tem elaborado uma variedade de mapas temáticos que permitem estudos mais aprofundados de temas geográficos numa perspectiva interdisciplinar.

A coleção da biblioteca deve apoiar as novas concepções do ensino da geografia, oferecendo, portanto, os tradicionais materiais de referência (enciclopédias, atlas, dicionários geográficos, livros-texto, jornais e revistas), além de uma variedade de materiais audiovisuais.

\section{MATEMÁTICA}

O ensino da Matemática nos PCN está ligado ao papel que essa área representa: a) na formação de capacidades intelectuais (generalizar, projetar, prever e abstrair, favorecendo a estruturação do pensamento e o desenvolvimento de raciocínio lógico); b) na aplicação a situações da vida cotidiana e no trabalho, e c) como instrumental para outras áreas curriculares. Em resumo, o conhecimento matemático é visto como uma competência que permitirá a inserção das pessoas no mundo do trabaIho, das relações sociais e da cultura, con- tribuindo para a construção da cidadania.

Convivendo desde cedo com situações que envolvem números, relações entre quantidades e noções sobre espaço as crianças têm, na fase de educação infantil, oportunidade de organizar melhor as informações e estratégias que desenvolvem para resolver as questões matemáticas com as quais se deparam no seu dia-a-dia. Iniciando, com crianças na faixa etária de zero a três anos, com atividades que envolvem contagem oral, noções de quantidade, de tempo e de espaço e possibilidades associativas de objetos, desenvolvidas através de jogos e brincadeiras organizadas, a aprendizagem da matemática, a partir dos quatro e até os seis anos, se organiza, segundo os PCN em três blocos, que devem ser vivenciados de maneira integrada pelas crianças: Números e sistema de numeração, Grandezas e medidas e Espaço e forma.

A coleção da biblioteca pode, nessa circunstância, caracterizar-se como uma brinquedoteca, reunindo uma variedade de jogos: dominós, baralhos, jogos com pistas, jogos espaciais e outros que apóiem a aprendizagem da matemática.

Comparativamente às outras áreas curriculares do ensino fundamental a Matemática depende pouco da biblioteca como espaço de busca e uso de materiais para a aprendizagem de seus conteúdos. Baseada na solução de problemas, onde o ponto de partida é a exploração do problema, com a criação de situações em que os alunos precisam desenvolver algum tipo de estratégia para resolvê-las, a Matemática também utiliza recursos como jogos e tecnologias da informação, principalmente na forma de simulações.

O estudo da história da Matemática é previsto nos PCN com o objetivo de revelar 
a Matemática como uma criação humana, contextualizando historicamente o conhecimento matemático e permitindo a criação de um olhar crítico sobre o mesmo. Nesse sentido, fontes como enciclopédias e livrostexto devem apoiar o ensino e portanto precisam estar presentes na coleção da biblioteca.

Outro apoio para a área de Matemática, a ser oferecido pela biblioteca, são os dados estatísticos e séries históricas, além de tabelas, gráficos, diagramas, etc. encontrados em textos jornalísticos, científicos e outros, contribuindo para uma aprendizagem que permita que o aluno analise dados organizados em representações matemáticas diversas.

\section{ARTE}

A Arte foi introduzida como uma área específica da estrutura curricular do ensino básico com a LDB de 1996 (Lei 9394). Assim como o contato com a obra literária pode propiciar uma forma diferente de apreensão do conhecimento, a aprendizagem da Arte permite o desenvolvimento do pensamento artístico que caracteriza um modo peculiar de dar sentido às experiências, ampliando a sensibilidade, a percepção, a reflexão e a imaginação do aluno. Nos PCN, a Arte tem uma função tão importante quanto a dos outros conhecimentos, relacionando-se com as outras áreas e apresentando certas especificidades.

A concepção pedagógica da Arte nos PCN tem como base a integração entre o fazer artístico, a apreciação da obra de arte e a contextualização histórica da arte.

Na educação infantil a Arte se faz presente nos conteúdos de música, artes visuais e movimento (dança). Consideradas pelos PCN como importantes formas de expressão e comunicação humanas as artes têm um lugar especial desde o início da escolarização, criando um espaço prazeroso para a criança expressar sua sensibilidade.

Baseada na articulação de três aspectos (o fazer artístico, a apreciação da obra de arte e a reflexão sobre os dois primeiros) a aprendizagem de artes não visa formar artistas mas crianças sensíveis e conhecedoras da linguagem da arte.

Nesse sentido, a biblioteca tem responsabilidade no fornecimento de uma variedade de materiais: livros de arte, reproduções, revistas especializadas, CDs de canções e músicas diversas, vídeos de danças folclóricas e populares.

No ensino fundamental a área de Arte contempla, além das três modalidades mencionadas anteriormente (música, artes visuais e dança), o teatro. Essa variedade de opções, bem como a ampliação da concepção do ensino de Artes (integrando o fazer artístico, a apreciação da obra de arte e contextualização histórica da arte) exige que a biblioteca responda com uma coleção rica e bem selecionada.

Especialmente no que tange a apreciação da obra de arte e a história da arte, a biblioteca pode oferecer apoio para a aprendizagem, fornecendo documentos que retratem objetos, materiais e técnicas artísticas, livros sobre história da arte, biografias de artistas, levantamento sobre artistas e artesãos locais, catálogos de exposições, etc.

No que diz respeito à música é necessário incorporar à coleção materiais representativos da variedade de estruturas sonoras existentes, não se esquecendo das linguagens musicais típicas da sociedade contemporânea, como jingles e trilhas so- 
noras produzidas para diversas finalidades.

\section{EDUCAÇÃO FÍSICA}

O processo de ensino/aprendizagem da Educação Física nos PCN não se limita ao desenvolvimento de certas habilidades e destrezas corporais, mas busca capacitar o aluno a refletir sobre suas possibilidades corporais, de forma a poder exercê-las com autonomia e de maneira significativa e adequada. Há uma preocupação em humanizar a prática pedagógica da área, ampliando-a de uma visão apenas biológica para um trabalho que incorpore dimensões afetivas, cognitivas e socioculturais.

No ensino fundamental, os conteúdos de Educação Física são obrigatórios em todo o período de escolaridade, da 1a. à 4a. séries, desde a promulgação da LDB (Lei 9394) em 1996, e se organizam em três blocos, conforme mostrado abaixo.
Os blocos são articulados entre si, com vários conteúdos em comum e algumas especificidades. O espaço privilegiado para aprendizagem da Educação Física, no que diz respeito às atividades práticas, continua sendo a quadra e, no caso das escolas brasileiras que muitas vezes não contam com esse espaço, o espaço adaptado de um pátio, um terreno próximo a escola, um campinho.

À primeira vista pode parecer que não há espaço para a biblioteca no que diz respeito ao fornecimento de material para apoio à aprendizagem da área. Entretanto, a necessidade de contextualizar a prática e de desenvolver nos alunos a capacidade de apreciação e crítica de diversas manifestação da cultura corporal, além de conhecimentos sobre o corpo, colocam para biblioteca a responsabilidade de fornecimento de inúmeros recursos informacionais para a área.

Livros-texto, enciclopédias e outros

\section{Blocos de Educação Física para o ensino fundamental}

\begin{tabular}{|c|c|}
\hline $\begin{array}{c}\text { Esportes, jogos, lutas e } \\
\text { ginásticas }\end{array}$ & $\begin{array}{c}\text { Atividades rítmicas e } \\
\text { expressivas }\end{array}$ \\
\hline \multicolumn{2}{|c|}{ Conhecimentos sobre o corpo } \\
\hline
\end{tabular}


materiais apóiam as aprendizagem de conceitos básicos de anatomia, fisiologia, bioquímica, que se apresentam de forma simplificada nas séries iniciais, ampliandose e aprofundando-se nas séries finais.

Atividades que visam contextualizar as práticas e desenvolver nos alunos a capacidade de apreciação e crítica de manifestações da cultura corporal vão exigir uma variedade de materiais audiovisuais que tratem de jogos de futebol e outros esportes, olimpíadas, capoeira etc., além de cadernos de esportes de jornais e de revistas especializadas.

\section{LÍNGUA ESTRANGEIRA}

O ensino de Língua Estrangeira é proposto nos PCN a partir do terceiro ciclo (5a./ 6a. séries) e constitui uma possibilidade de aumentar a autopercepção do estudante como ser humano e como cidadão, desenvolvendo sua consciência crítica, no que diz respeito ao modo como a linguagem é usada no mundo social, como reflexo de crenças, valores e projetos políticos.

A aprendizagem de língua estrangeira é baseada em textos orais e escritos e, nesse sentido deve utilizar aqueles gêneros com os quais os alunos já estejam familiarizados como usuários da língua materna.

Os PCN propõem uma relação direta entre os temas transversais e o ensino de Língua Estrangeira, de forma a permitir que os alunos possam compreendê-los por meio de discursos construídos em outros contextos sociais e aprendam a pensar criticamente sobre eles.

A utilização de tipos de textos variados, além de contribuir para o aumento do conhecimento intertextual do aluno, ajuda a mostrar que os textos são usados socialmente, com propósitos diferentes. Por exemplo, editoriais de vários jornais e revistas podem ser usados para comparar pontos de vistas conflitantes.

O ensino de Língua Estrangeira progride a partir de um enfoque no conhecimento de mundo do aluno (sua vida em família, na escola, no lazer, na sociedade, no país e no mundo) e na organização textual com a qual já esteja familiarizado através do estudo da língua materna. Para esse enfoque inicial os $\mathrm{PCN}$ sugerem pequenas histórias, quadrinhas, histórias em quadrinhos, instruções de jogos, anedotas, travalínguas, anúncios, pequenos diálogos, rótulos de embalagens, cartazes, canções, pequenas notícias, entrevistas, programação de TV, textos publicitários, cartas, reportagens, poemas, editoriais de jornais, artigos jornalísticos, textos de enciclopédias, verbetes de dicionários, estatutos, declarações de direitos. Outros recursos informacionais serão necessários, dependendo da metodologia adotada: o uso de computador, gravador e televisão nas aulas de Língua Estrangeira vão exigir materiais audiovisuais e softwares específicos.

\section{TEMAS TRANSVERSAIS}

Tendo como objetivo final a construção da cidadania, a proposta educativa dos PCN introduz o conceito de transversalidade, uma nova forma de organizar o trabalho didático que se concretiza na definição dos chamados temas transversais. São eles: Ética, Pluralidade Cultural, Meio Ambiente, Saúde, Orientação Sexual, Trabalho e Consumo. Não constituem novas áreas ou disciplinas mas sim questões urgentes e presentes na vida cotidiana, que devem permear as atividades es- 
colares nas diversas áreas curriculares.

Os Temas Transversais foram escoIhidos de forma a viabilizar as propostas dos PCN, de educar para a democracia para o presente e não para o futuro, baseando-se nos princípios da dignidade da pessoa humana, igualdade de direitos, participação e co-responsabilidade na vida social.

A biblioteca constitui um espaço privilegiado de materiais que embasam a aprendizagem dos Temas Transversais, cujos eixos são apresentados em blocos de conteúdo conforme mostrado na página ao lado.

Conceitos básicos relativos aos Temas Transversais estarão presentes em fontes tradicionais, como enciclopédias, livros-texto e outras, mas a atualidade inerente aos conteúdos vai exigir uma base documentária variada e ampla, que deverá ser buscada em fontes alternativas e mantida em constante atualização.

\section{CONCLUSÃO}

A concepção pedagógica proposta nos PCN vem, com certeza, reforça o papel da biblioteca dentro da escola. Ela se constituirá no espaço coletivo para o compartilhamento dos recursos didáticos que as novas metodologias irão exigir. Fica evidente que esses recursos deverão estar próximos dos alunos, não se justificando mais soluções paliativas que sugeriam que a biblioteca pública poderia substituir a biblioteca escolar.

A partir das diretrizes dos $\mathrm{PCN}$, no que diz respeito aos materiais que irão embasar a aprendizagem, observa-se que a característica mais evidente do acervo da biblioteca escolar é a diversidade. Baseada nos "textos de fato" a aprendizagem proposta nos PCN exige uma coleção que contemple a "diversidade de textos que circulam socialmente". Ora, esses textos podem aparecer em suportes variados e, portanto o acervo da biblioteca deve contemplar essa variedade, oferecendo opções ou selecionando a mais adequada.

A questão da variedade de suportes informacionais teve influência na própria denominação da biblioteca escolar nos Estados Unidos, quando, naquele país, a instituição passou a se denominar "school library media center" ou "media resources center", reforçando-se sua característica de um centro que oferecia recursos não apenas na forma impressa, mas também numa gama de suportes audiovisuais (Stripling, 1994). Atualmente, essa característica se exacerba, em função dos suportes eletrônicos em geral e da Internet em particular, e a biblioteca se transforma num espaço de informação virtual.

Essa característica, que implica na existência de equipamentos, vai ter influência em vários aspectos do planejamento da biblioteca, entre eles no layout, que deverá ser desenhado com espaços diversificados, de acordo com as necessidades de utilização dos materiais disponíveis.

Não se pode deixar de mencionar a Internet como uma rica fonte de informação para apoiar os trabalhos escolares. Embora seja um recurso utilizado pelos alunos principalmente em ambientes domésticos (CAMPELLO, 2000b), a biblioteca não pode ignorá-la. A influência da biblioteca no uso da rede pode se dar especialmente na seleção e divulgação de sites de boa qualidade e adequados aos conteúdos e aos estágios de desenvolvimento dos alunos. O uso de recursos hipertextuais e interativos devem ser estimulados e, no caso de a biblioteca não ter acesso à Internet mas contar com computador, os 


\section{Blocos de conteúdos dos Temas Transversais}

\begin{tabular}{|c|c|}
\hline Ética & $\begin{array}{l}\text { Respeito mútuo } \\
\text { Justiça } \\
\text { Diálogo } \\
\text { Solidariedade }\end{array}$ \\
\hline $\begin{array}{l}\text { Pluralidade } \\
\text { Cultural }\end{array}$ & $\begin{array}{l}\text { Pluralidade Cultural e a vida das crianças no Brasil } \\
\text { Espaço e pluralidade } \\
\text { Tempo e pluralidade } \\
\text { Vida sociofamiliar e comunitária } \\
\text { Constituição da Pluralidade cultural no Brasil e situação atual } \\
\text { Continentes e terras de origem dos povos do Brasil } \\
\text { Trajetórias das etnias no Brasil } \\
\text { Situação atual } \\
\text { O ser humano como agente social e produtor de cultura } \\
\text { Linguagens da pluralidade nos diferentes grupos } \\
\text { étnicos e culturais no Brasil } \\
\text { Línguas } \\
\text { Produção de conhecimento } \\
\text { Pluralidade Cultural e cidadania } \\
\text { Organização política e pluralidade } \\
\text { Pluralidade e direitos } \\
\text { Situações urgentes no Brasil em relação aos } \\
\text { direitos da criança } \\
\text { Fortalecendo a cidadania }\end{array}$ \\
\hline Meio ambiente & $\begin{array}{l}\text { Os ciclos da natureza } \\
\text { Sociedade e meio ambiente } \\
\text { Manejo e conservação ambiental }\end{array}$ \\
\hline Saúde & $\begin{array}{l}\text { Auto conhecimento para o auto cuidado } \\
\text { Vida coletiva }\end{array}$ \\
\hline $\begin{array}{l}\text { Orientação } \\
\text { Sexual }\end{array}$ & $\begin{array}{l}\text { Corpo: matriz da sexualidade } \\
\text { Relação de gênero } \\
\text { Prevenção doenças sexualmente transmissíveis/AIDS }\end{array}$ \\
\hline $\begin{array}{l}\text { Trabalho e } \\
\text { consumo }\end{array}$ & $\begin{array}{l}\text { Direito } \\
\text { Trabalho e sociedade } \\
\text { Consumo, meios de comunicação, publicidade } \\
\text { Trabalho, consumo e meio ambiente } \\
\text { Trabalho, consumo e saúde }\end{array}$ \\
\hline
\end{tabular}


CD-ROMs educativos podem ser uma boa opção.

Uma política de formação e desenvolvimento de acervo elaborada de acordo com o projeto pedagógico da escola e com os planos didáticos dos professores será necessária para garantir o equilíbrio e a consistência da coleção.

O trabalho integrado de bibliotecários e professores no planejamento das atividades escolares garantirá a adequação do acervo ao projeto pedagógico da escola.

\section{REFERÊNCIAS}

BRASIL. Secretaria de Educação Fundamental. Parâmetros Curriculares Nacionais, 1.a 4. séries. Brasília: MEC, 1997. 10 v.

BRASIL. Secretaria de Educação Fundamental. Parâmetros Curriculares Nacionais, 5.a 8. séries. Brasília: MEC, 1998. 10 v.

BRASIL. Secretaria de Educação Fundamental. Referencial Curricular Nacional para a Educação Infantil. Brasília: MEC, 1998. 3 v.

CAMPELLO, B. S., SILVA, M. A. A biblioteca nos Parâmetros Curriculares Nacionais. Presença Pedagógica, v. 6, n. 33, p. 59-67, mai./jun. 2000a.

CAMPELLO, B. S. et al. A internet na pesquisa escolar: um panorama do uso da web por alunos do ensino fundamental. In: CONGRESSO BRASILEIRO DE BIBLIOTECONOMIA E DOCUMENTAÇÃO, 19., 2000, Porto Alegre. Anais ... Porto Alegre: ARB/FEBAB, 2000. v. 1. (cd-rom).

MAYRINK, Paulo Tarcísio. Diretrizes para a formação de bibliotecas escolares. In: CONGRESSO BRASILEIRO DE BIBLIOTECONOMIAE DOCUMENTAÇÃO, 16, 1991, Salvador. Anais. Salvador: APBEB, 1991. v. 1, p. 304-314 .

SILVA, E. T. Ensino e biblioteca. Releitura, Belo Horizonte, n. 10, p. 53-56, junho 1997. 
STRIPLING, B. K. Quality in school library media programs: focus on learning. Library Trends, v. 44, n. 3, p. 631-656, 1994.

\section{Bernadete Santos Campello}

Professora da Escola de Ciência da Informação da UFMG (ECI/UFMG)

Carlos Henrique de Magalhães Bolsistas de Iniciação Científica (CNPq e Fapemig)

Giovanna Vasconcellos Xavier Bolsistas do Programa de Aperfeiçoamento Discente do Colegiado do Curso de

Biblioteconomia da ECI/UFMG

\section{Leonardo da Costa Diskin}

Bolsistas do Programa de Aperfeiçoamento Discente do Colegiado do Curso de

Biblioteconomia da ECI/UFMG

\section{Márcia Margarida Vilaça}

Bolsistas do Programa de Aperfeiçoamento Discente do Colegiado do Curso de Biblioteconomia da ECI/UFMG

\section{Simone Alves Diamantino}

Bolsistas de Iniciação Científica (CNPq e Fapemig)

\section{Sirlene Aparecida dos Santos}

Bolsistas do Programa de Aperfeiçoamento Discente do Colegiado do Curso de Biblioteconomia da ECI/UFMG

Waldete Rodrigues dos Santos

Bolsistas do Programa de Aperfeiçoamento Discente do Colegiado do Curso de Biblioteconomia da ECI/UFMG 


\section{Title}

The school library collection and the Brazilian Guidelines for Elementary Education

\begin{abstract}
The Brazilian Guidelines for Elementary Education constitute a series of propositions to support curriculum development and reeestructuring. The propositions are based on the constructivist approach to learning. This new concept of education demands a type of learning environment in which a variety of materials is needed in order to support the student's active participation in the learning process. Through an analysis of the Guidelines, this paper identifies materials the school library should have to face the demand for abundant learning materials necessary to support innovative learning methods.
\end{abstract}

\section{Keywords}

Learning material; Library collection

\section{Titulo}

La colección de la biblioteca escolar según la perspectiva de los parâmetros curriculares nacionales

\section{Resumen}

Los Parámetros Curriculares Nacionales (PCN) constituyen directrices para la reestructuración curricular de las escuelas de enseñanza fundamental y educación infantil en Brasil. La propuesta de los PCN es de una enseñanza basada en la perspectiva constructivista $y$, para lo cual, la escuela necesita contar con el material didáctico variado. Considerando que la biblioteca es el local por excelencia para reunir y compartir de esos materiales, se procura, en este trabajo, esbozar el perfil de la colección de una biblioteca comprometida con metodologías de aprendizaje innovadores. Identifica en los PCN los materiales y las temáticas sugeridas y, entonces, fue delineado el perfil de la colección.

\section{Palabras-Clave}

Biblioteca Escolar; Material Didáctico; Lectura; Parámetros Curriculares Nacionales 